Proc. Indian Acad. Sci. (Chem. Sci.), Vol. 109, No. 3, June 1997, pp. 203-209.

(C) Printed in India.

\title{
Study of the role of sodium hypophosphite in electroless nickel bath solution
}

\author{
T MIMANI and S M MAYANNA* \\ Department of Post Graduate Studies in Chemistry, Central College, Bangalore \\ University, Bangalore 560001, India \\ MS received 20 January 1997; revised 10 April 1997
}

\begin{abstract}
Cyclic voltametric investigations have been made to understand the electrochemical behaviour of sodium hypophosphite in electroless plating bath solution. The possible reaction steps at the anode and cathode have been identified. An ECE type of mechanism appears to be operative in the overall reaction during electroless plating. Both organic and inorganic species in the bath solution influence the voltammetric pattern of the hypophosphite. Temperature enhances the peak currents and changes the reaction mechanism. The oxidation potentials of the reaction steps vary with temperature and also the presence of organic components in the bath solution.
\end{abstract}

Keywords. Electroless plating; cyclic voltammetry; electrochemical behaviour; sodium hypophosphite.

\section{Introduction}

In recent years, electroless nickel (EN) coating technology has attained considerable significance in metal-finishing industries. However, the problems associated with the process continue to draw the attention of researchers owing to the lack of comprehensive and basic understanding of the system (Mallory and Hajdu 1990; Ridel 1991).

In electroless plating, the metal reductant plays a significant role in driving the plating process. Polarisation (Flis and Duquette 1984; Crousier et al 1993) and voltammetric (Podesta et al 1990) studies have been made with sodium hypophosphite as reducing agent in EN plating bath solutions. However, the proposed mechanisms are not adequate for explaining the overall reaction. Hence, an attempt is made here to study the possible reactions of sodium hypophosphite (SHP) in the presence of bath constituents through the cyclic voltammetric technique.

\section{Experimental}

Solutions were prepared using distilled water and analytical grade chemicals. Experiments were carried out using acidic $\left(p \mathrm{H}\right.$ 5) $0.15 \mathrm{M} \mathrm{NaH}_{2} \mathrm{PO}_{2}$ solution at ambient temperature. The composition of each solution component was varied as and when required. The solution of sodium hypophosphite being a good electrolyte, the need for using other supporting electrolytes did not arise. The detailed experimental

\footnotetext{
*For correspondence
} 
procedures adopted in the present investigations were similar to those given earlier (Mimani et al 1993).

An all-glass single compartment cell was used, wherein the working and counter electrodes were platinum foils $\left(0.5 \mathrm{~cm}^{2}\right)$ with saturated calomel electrode as the reference. The solutions were deaerated by bubbling pure nitrogen gas before every run. A PAR model Scanning Potentiostat 362 was used to record the data. Reproducible voltammograms were obtained on repeated scanning.

\section{Results}

The electrochemical reactions of $0 \cdot 15 \mathrm{M}$ sodium hypophosphite (SHP) at $p \mathrm{H} 5$ were obtained by cycling the potential from $-0.25 \mathrm{~V}$ to $1.20 \mathrm{~V}$ at different scan rates (figure 1). The voltammograms show an anodic hump $i_{p a}^{1}$ followed by a large anodic peak $i_{p a}^{2}$ and a small cathodic peak $i_{p c}$. From the results obtained at different scan rates, a plot of $i_{p}$ values of peak $i_{p a}^{2}$ versus $\gamma^{1 / 2}$ is made. A straight line passing through the origin depicts the irreversible nature of the reaction as observed earlier (Podesta et al 1990). The peak $i_{p c}$ appeared only if the potential is scanned to the region of $i_{p a}^{2}$ which indicated the inter-relationship between $i_{p a}^{2}$ and $i_{p c}$.

Most of the developed EN baths containing SHP operate at higher temperature ranges. Hence, it was felt that it was necessary to study the effect of temperature on the

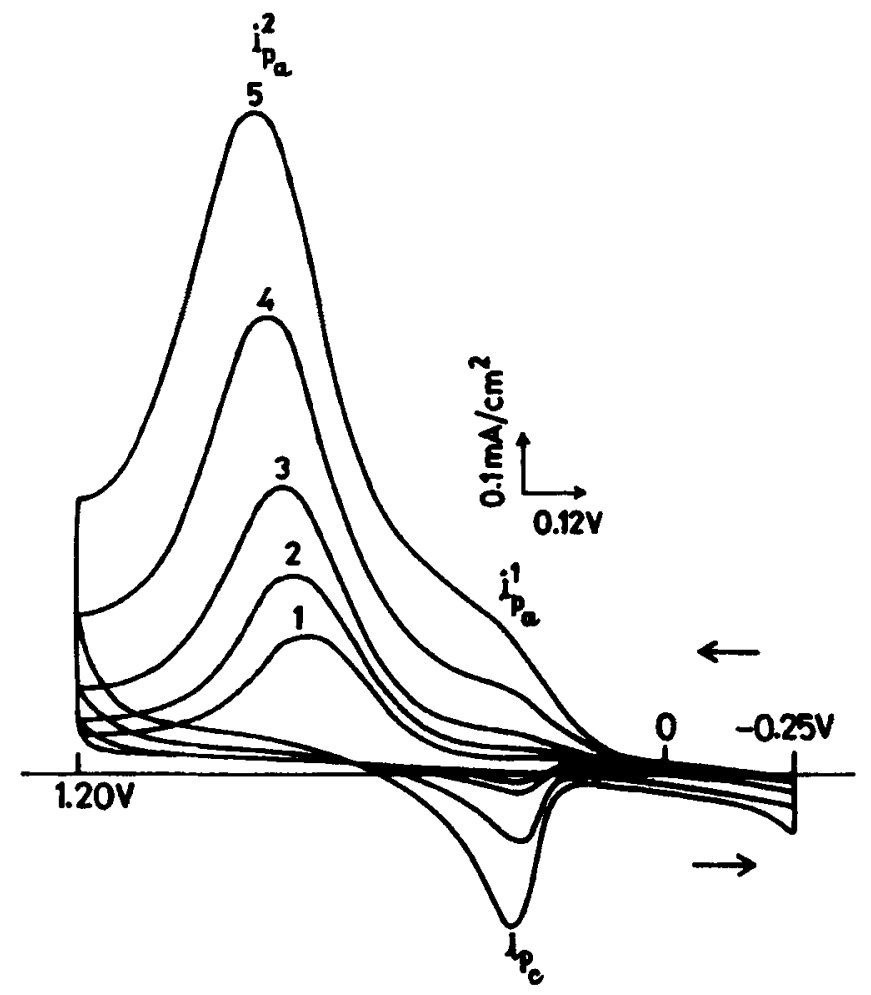

Figure 1. Cyclic voltammograms obtained on platinum with $0.15 \mathrm{M}$ SHP at $p \mathrm{H} 5$ in the potential range -0.25 to $1.20 \mathrm{~V}$, as a function of sweep rate: (1) 100 , (2) 50, (3) 20, (4) 10 and (5) $5 \mathrm{mVs}^{-1}$ 


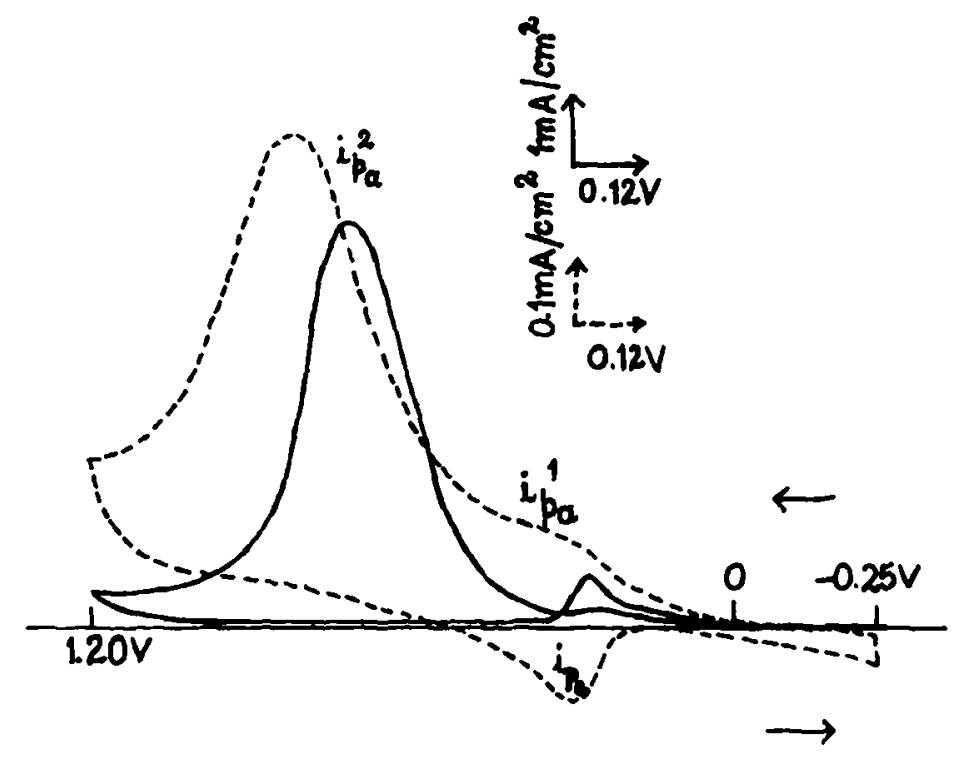

Figure 2. Cyclic voltammograms obtained on platinum with $0.15 \mathrm{M}$ SHP at $p \mathrm{H} 5$ in the potential range -0.25 to $1.20 \mathrm{~V}$ at a scan rate $50 \mathrm{~m} \mathrm{Vs}^{-1}(----298 \mathrm{~K}$; - - $343 \mathrm{~K}$ )

voltammetric pattern. A typical voltammogram with $0 \cdot 15 \mathrm{M}$ SHP at $\mathrm{pH} 5$ and temperature $343 \mathrm{~K}$ is shown in figure 2 . The voltammetric behavior in the anodic cycle is almost similar to that at ambient temperature. However, peak current is increased nearly tenfold and peak potential $i_{p a}^{2}$ shifts to lower values. In the cathodic cycle, the $i_{p c}$ current is initially cathodic and then inverts to the anodic side at more negative potentials.

Experiments were conducted in the presence of additives which are commonly used in plating bath solutions. Boric acid (BA), sodium sulphate (SS) and sodium chloride (SC) at $0.5 \mathrm{M}$ each and nickel sulphate (NS) at $0.1 \mathrm{M}$ were added individually to $0.15 \mathrm{M}$ SHP at $p \mathrm{H}$ 5. Some of these commonly present ions in the EN bath were found to affect the reaction of the SHP by varying either the peak potentials or the current (table 1).

The influence of organic acids or salts on the cyclic voltammogram was also studied. Sodium acetate (SA), lactic acid (LA), sodium potassium tartrate (SPT) and sodium citrate (SCI) with a concentration of $0.4 \mathrm{M}$ were added individually to $0.15 \mathrm{M} \mathrm{SHP}$ at $p \mathrm{H}$ 5. Change in the $i_{p}$ 's and $E_{p}$ 's with evolution of gas at the extreme positive potential values is noticed (table 1). The shift in potential is in the order,

$$
(\mathrm{SCI})>(\mathrm{SA})>(\mathrm{SPT}) \text {. }
$$

Further, the additives BA $(0.5 \mathrm{M})$, SPT $(0.4 \mathrm{M})$, SC $(0.5 \mathrm{M})$, NS $(0.1 \mathrm{M})$ and SCI $(0.4 \mathrm{M})$ when added at $p \mathrm{H} 5$ in various combinations affected the $i_{p}$ 's and $E_{p}$ 's to different extents (figure 3).

\section{Results and discussion}

It is known that hypophosphite can be oxidized chemically to phosphate (Van Wazer 1958). The voltammetric pattern (figure 1), however, shows a hump $i_{p a}^{1}$ and a broad peak 
Table 1. The variation of peak currents $\left(i_{p}\right)$ and peak potentials $\left(E_{p}\right)$ in $0 \cdot 15 \mathrm{SHP}$ at $p \mathrm{H} 5$ and $303 \mathrm{~K}$ in the presence of different additives at a scan rate of $50 \mathrm{mVs}^{-1}$.

\begin{tabular}{|c|c|c|c|c|c|c|c|c|c|}
\hline \multirow[b]{2}{*}{ Peak } & & \multicolumn{4}{|c|}{ Inorganic components } & \multicolumn{4}{|c|}{ Organic components } \\
\hline & & BA & SS & $\mathrm{SC}$ & SHP & SA & LA & SCI & SPT \\
\hline \multirow{2}{*}{$i_{p a}^{2}$} & $i_{p}^{*}$ & 0.650 & 0.920 & 0.460 & $0 \cdot 740$ & 0.360 & $0 \cdot 370$ & 0.320 & 0.360 \\
\hline & $E_{p / v}^{+}$ & $0 \cdot 786$ & $0-750$ & 0.900 & $0 \cdot 774$ & 0.636 & 0.684 & 0.636 & 0.774 \\
\hline \multirow{2}{*}{$i_{p c}$} & $i_{p}^{*}$ & 0.080 & 0.090 & 0.050 & $0 \cdot 120$ & $0-240$ & $0 \cdot 210$ & $0 \cdot 190$ & 0.020 \\
\hline & $E_{p}^{+}$ & $0 \cdot 324$ & $0 \cdot 324$ & 0.396 & $0 \cdot 280$ & $0 \cdot 204$ & $0 \cdot 216$ & 0.216 & $0 \cdot 216$ \\
\hline
\end{tabular}

${ }^{*}$ in $\mathrm{mA} / \mathrm{cm}^{2} ;{ }^{+}$in $\mathrm{V}$

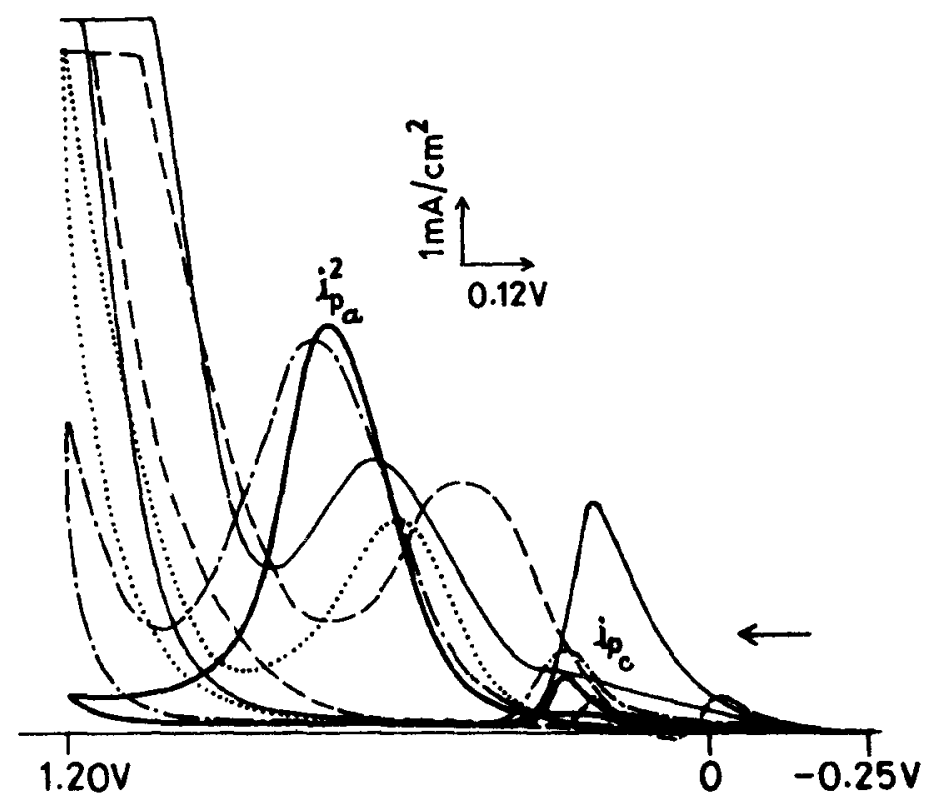

Figure 3. Cyclic voltammograms obtained on platinum with $0.15 \mathrm{M}$ SHP at $343 \mathrm{~K}$ and $p \mathrm{H} 5$ in the potential range -0.25 to $1.20 \mathrm{~V}$ at a scan rate $50 \mathrm{mVs}^{-1}($ $\mathrm{SHP} ;-\ldots \mathrm{BA}+\mathrm{SC} ;-\mathrm{NS}+\mathrm{BA}+\mathrm{SC}+\mathrm{SCI} ; \ldots \ldots . \mathrm{BA}+\mathrm{SPT}$; $\mathrm{BA}+\mathrm{SC}+\mathrm{SPT})$.

$i_{p a}^{2}$ confirming that the oxidation is not a single-step process but involves an intermediate. Based on the observed results, the following mechanism for the oxidation process can be proposed. 
At $i_{p c}^{1}$, the oxidation of the hypophosphite to hypophosphate takes place at the electrode surface (Griffith et al 1940):

$$
\begin{aligned}
& \mathrm{H}_{2} \mathrm{PO}_{2}^{-}+\mathrm{H}_{2} \mathrm{O} \rightarrow \mathrm{H}_{2} \mathrm{PO}_{3}^{-}+2 \mathrm{H}^{+}+2 e, \\
& \mathrm{H}_{2} \mathrm{PO}_{3}^{-} \rightleftharpoons \mathrm{HPO}_{3}^{2-}+\mathrm{H}^{+} .
\end{aligned}
$$

The hypophosphate ion is in equilibrium with the phosphite ion (Cotton and Wilkinson 1990) which is less stable. It easily gets oxidised to the phosphate, which results in the peak $a_{p}^{2}$ (Blaser 1993).

$$
\mathrm{HPO}_{3}^{2-}+\mathrm{H}_{2} \mathrm{O} \rightarrow \mathrm{H}_{2} \mathrm{PO}_{4}^{-}+\mathrm{H}^{+}+2 e
$$

On reversing the scan after $i_{p a}^{2}$, the immediate reduction of the phosphate is not observed. The reason could be that after the electrochemical oxidation, a slow chemical reduction takes place to generate the hypophosphite species as proposed earlier, in the electrochemical reduction of phosphates (Franks and Inman 1970).

$$
\mathrm{H}_{2} \mathrm{PO}_{4}^{-} \rightarrow \mathrm{H}_{2} \mathrm{PO}_{2}^{-}+\mathrm{O}_{2} \text {. }
$$

The phosphite then gets reduced to form phosphine (Bard 1975).

$$
\mathrm{H}_{2} \mathrm{PO}_{2}^{-}+5 \mathrm{H}^{+}+4 e \rightarrow \mathrm{PH}_{3}+2 \mathrm{H}_{2} \mathrm{O} \text {. }
$$

It is observed that the $i_{p}$ of $i_{p a}^{2}$ increases while that of $i_{p c}$ decreases with the increase in concentration of SHP. This non-proportionality in the peak currents and the increase in the $i_{p}$ of $i_{\mathrm{pc}}$, on stirring, support the fact that reaction (5) is diffusion controlled by the preceeding slow chemical reaction (4). This step could be the most probable path for the observed production of phosphine (Ratzkar et al 1986) during electroless plating.

At a higher temperature, the shift in potential $\left(i_{p a}^{2}\right)$ to lower value suggests the ease of hypophosphite oxidation to phosphate. From the reversal of the cathodic current of $i_{p c}$ to anodic (figure 2), it is inferred that after the onset of the cathodic reaction, an anodic reaction of the type

$$
\mathrm{PH}_{3} \rightarrow \mathrm{P}+3 \mathrm{H}^{+}+3 e
$$

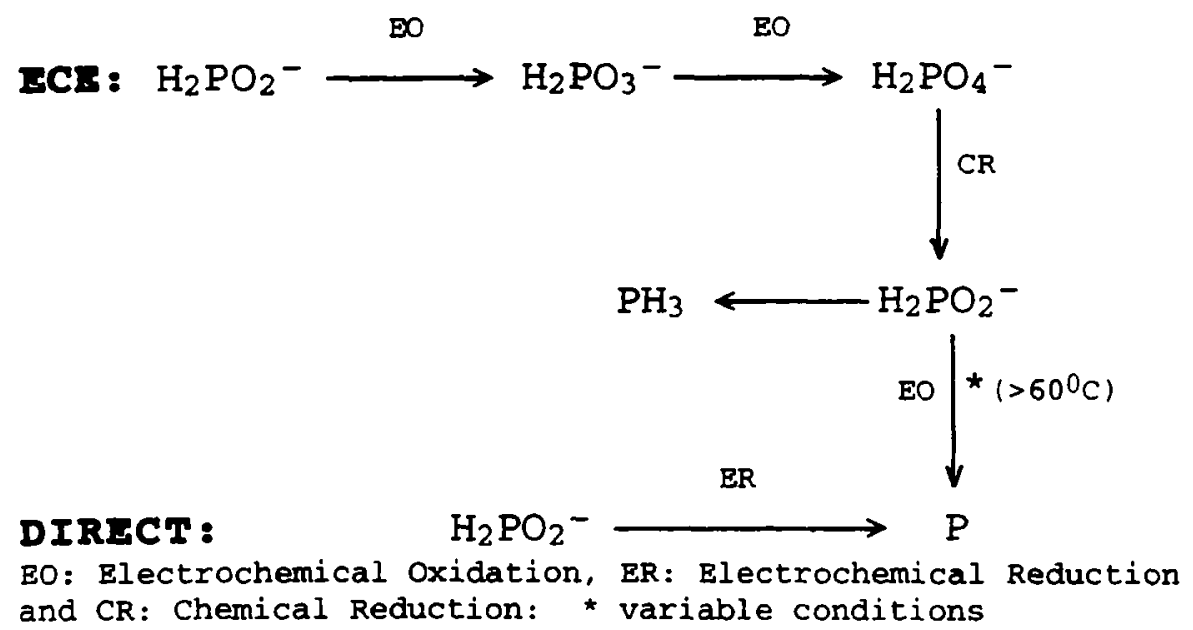


occurs to produce phosphorus (De Bethane et al 1961). Based on the above reactions, an overall mechanism scheme for the role of hypophosphite in the electroless plating baths could be proposed.

The feasibility of a direct mechanism as reported earlier (De Bethane et al 1961; Gafin and Orchard 1992) appears to be less relevant, because in such a case, the process would begin with hypophosphite reduction giving either an equal or an even larger amount of phosphorus content in the deposit than nickel. This is contrary to the observed results. In the case of the ECE mechanism, the process begins with the oxidation step to initiate the electrochemical reduction of the nickel ion. Because of the slow chemical reaction after the phosphate stage, the formation of phosphorus gets kinetically controlled.

In the presence of the organic ions, the influence on the oxidation of the SHP is more distinct. The hydroxy carboxylic acids are known to form acyl phosphates or esters with hypophosphites (Burt and Simpson 1969),

$$
\mathrm{RC}(\mathrm{O}) \mathrm{OH}+\mathrm{H}_{2} \mathrm{PO}_{2}^{-} \rightarrow \mathrm{RC}(\mathrm{O}) \mathrm{OP}(\mathrm{O}) \mathrm{H}_{2}+\mathrm{OH}^{-} \text {, }
$$

The electrochemical process then proceeds from the hypophosphite ester to the phosphate ester (Kazlauskas and Whitesides 1985) in a manner proposed in the above mechanism.

$$
\begin{aligned}
& \mathrm{RC}(\mathrm{O}) \mathrm{OP}(\mathrm{O}) \mathrm{H}_{2}+\mathrm{H}_{2} \mathrm{O} \rightarrow \mathrm{RC}(\mathrm{O}) \mathrm{OP}(\mathrm{O}) \mathrm{OH}_{2}+2 \mathrm{H}^{+}+2 e \\
& \mathrm{RC}(\mathrm{O}) \mathrm{OP}(\mathrm{O}) \mathrm{OH}_{2}+\mathrm{H}_{2} \mathrm{O} \rightarrow \mathrm{RC}(\mathrm{O}) \mathrm{OP}(\mathrm{O})(\mathrm{OH})_{2}+2 \mathrm{H}^{+}+2 e .
\end{aligned}
$$

At the positive end, the evolution of oxygen or carbon dioxide takes place due to the presence of hydroxyl and carboxylate groups. The lowering of potentials of $i_{p a}^{2}$ by $\sim 150 \mathrm{mV}$ shows the ease of oxidation of SHP in the presence of these organic acids.

The CV pattern is not affected at ambient or higher temperatures in presence of (BA) or (SC) in the SHP solution. But the addition of (SPT) or (SCI) or (NS) reduces the peak potential of $i_{p a}^{2}$, while (NS) increases the $i_{p}$ of $i_{p c}$ to a considerable extent. The peak potential which is lowered in the presence of boric acid and tartrate is further lowered in the presence of sodium chloride. Thus, the role of the chloride ion in enhancing the oxidation of the hypophosphite is clearly seen. The increase of $i_{p}$ of $i_{p c}$ supports the earlier findings that nickel ions catalyze the co-deposition of phosphorus in EN bath solutions (Brenner 1963; Harris and Dang 1993).

\section{Conclusions}

From these studies it is concluded that in the EN plating systems the bath constituents not only influence the reaction of the metal ion but also the reducing agent. The effect of $p \mathrm{H}$ and temperature on the oxidation potential of the phosphate formation suggests the need to carefully control the $p \mathrm{H}$ value and temperature during the EN process specially in the acid baths. The proposed mechanism explains the incorporation of phosphorus in the EN deposits. The organic acids which are thought to be behaving as complexing agents for the metal ion, have a greater role to play by way of enhancing the oxidation of the hypophosphite. The individual effect of the additive appears to be less pronounced when compared to the combined effect.

\section{Acknowledgements}

One of the authors (TM) thanks the Council of Scientific and Industrial Research, New Delhi for the award of a research fellowship. 


\section{References}

Bard A J (ed.) 1975 Encyclopedia of electrochemistry of the elements (New York: Marcel Dekker) vol. II-I, p. 4

Blaser B 1993 Z. Phys. Chem. A166 64

Brenner A 1963 Electrodeposition of alloys (New York: Academic Press) vol. 2, p. 457

Burt W and Simpson P 1969 J. Chem. Soc. 2273

Cotton F A and Wilkinson G 1990 Advanced inorganic chemistry, A comprehensive text 3 rd edn. (New Delhi: Wiley Eastern) ch. 13, p 394

Crousier J, Hanane Z and Crousier JP 1993 Electrochim. Acta 38261

De Bethane A J, Licht T S and Swendeman N 1961 J. Electrochem. Soc. 108616

Flis J and Duquette D J 1984 J. Electrochem. Soc 131254

Franks E and Inman D 1970 J. Electroanal. Chem. 2613

Gafin A H and Orchard S W $1992 J$. Appl. Electrochem. 22830

Griffith R O, Mckeown A and Tayloe R P 1940 Trans. Faraday Soc. 36752

Harris T M and Dang Q D 1993 J. Electrochem. Soc. 14081

Kazlauskas R J and Whitesides G M 1985 J. Org. Chem. 501069

Mallory G O and Hajdu J B 1990 Electroless plating, fundamentals and applications (Orlando, FL: AESF) p. 207

Mimani T, Mayanna S M and Munichandraiah N 1993 J. Appl. Electrochem. 23339

Podesto J J, Piatti R C V and Arvia A J 1990 J. Appl. Electrochem. 20245

Ratzker M, Lashmore D and Pratt K 1986 Plat. Surf. Finish. 74

Ridel D 1991 Electroless nickel plating (Stevenage, Harts: Finishing Publications)

Van Wazer J R 1958 Phosphorus and its compounds (New York: Interscience) vol. 1, ch. 7 , p. 364 